Review

\title{
Practical approach on frail older patients attended for acute heart failure
}

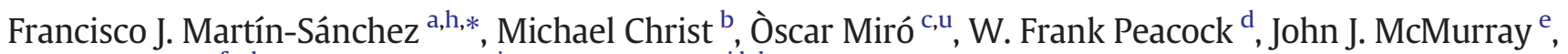 Héctor Bueno ${ }^{\mathrm{f}, \mathrm{g}, \mathrm{h}}$, Alan S. Maisel ${ }^{\mathrm{i}}$, Louise Cullen ${ }^{\mathrm{j}, \mathrm{k}, \mathrm{l}}$, Martin R. Cowie ${ }^{\mathrm{m}}$, Salvatore Di Somma ${ }^{\mathrm{n}}$, Elke Platz ${ }^{\mathrm{o}}$, Josep Masip ${ }^{\mathrm{p}, \mathrm{v}}$, Uwe Zeymer ${ }^{\mathrm{q}}$, Christiaan Vrints ${ }^{\mathrm{r}}$, Susanna Price ${ }^{\mathrm{s}}$, Christian Mueller ${ }^{\mathrm{t}, \mathrm{w}}$}

a Emergency Department, Hospital Clínico San Carlos, Instituto de Investigación Sanitaria Hospital Clínico San Carlos (IdISSC), Spain

${ }^{\mathrm{b}}$ Department of Emergency and Critical Care Medicine, Klinikum Nürnberg, Germany

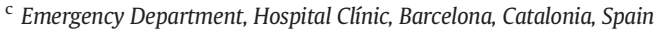

d Emergency Medicine, Baylor College of Medicine, Houston, TX, United States

e British Heart Foundation Cardiovascular Research Centre, University of Glasgow, Glasgow, United Kingdom

${ }^{\mathrm{f}}$ Centro Nacional de Investigaciones Cardiovasculares (CNIC), Madrid, Spain

${ }^{g}$ Instituto de Investigación $i+12$ y Servicio de Cardiología, Hospital Universitario 12 de Octubre, Madrid, Spain

${ }^{\text {h }}$ Universidad Complutense de Madrid, Madrid, Spain

i Coronary Care Unit and Heart Failure Program, Veteran Affairs (VA) San Diego, United States

j Department of Emergency Medicine, Royal Brisbane and Women's Hospital, Brisbane, Australia

k School of Public Health, Queensland University of Technology, Brisbane, Australia

${ }^{1}$ School of Medicine, The University of Queensland, Brisbane, Australia

${ }^{\mathrm{m}}$ Cardiology Department, Imperial College London (Royal Brompton Hospital), London, England, United Kingdom

${ }^{\mathrm{n}}$ Emergency Medicine, Department of Medical-Surgery Sciences and Translational Medicine, Sant'Andrea Hospital, University La Sapienza, Rome, Italy

${ }^{\circ}$ Department of Emergency Medicine, Brigham and Women's Hospital, Harvard Medical School, Boston, USA

p ICU Department, Consorci Sanitari Integral, University of Barcelona, Barcelona, Spain

${ }^{\mathrm{q}}$ Klinikum Ludwigshafen und Institut für Herzinfarktforschung Ludwigshafen, Ludwigshafen, Germany

${ }^{\mathrm{r}}$ Faculty of Medicine and Health Sciences, University of Antwerp, Antwerp, Belgium

${ }^{\mathrm{s}}$ Royal Brompton and Harefield National Health Service Foundation Trust, United Kingdom

${ }^{t}$ Department of Cardiology, University Hospital Basel, Basel, Switzerland

" Institut de Recerca Biomàdica August Pi i Sunyer (IDIBAPS), Barcelona, Catalonia, Spain

v Cardiology Department, Hospital Sanitas CIMA, Barcelona, Spain

${ }^{w}$ Cardiovascular Research Institute Basel (CRIB), University Hospital Basel, Basel, Switzerland

\section{A R T I C L E I N F O}

\section{Article history:}

Received 17 May 2016

Accepted 15 July 2016

Available online 18 July 2016

\section{Keywords:}

Frailty

Older

Acute heart failure

\section{A B S T R A C T}

Acute heart failure (AHF) is a multi-organ dysfunction syndrome. In addition to known cardiac dysfunction, noncardiac comorbidity, frailty and disability are independent risk factors of mortality, morbidity, cognitive and functional decline, and risk of institutionalization. Frailty, a treatable and potential reversible syndrome very common in older patients with AHF, increases the risk of disability and other adverse health outcomes. This position paper highlights the need to identify frailty in order to improve prognosis, the risk-benefits of invasive diagnostic and therapeutic procedures, and the definition of older-person-centered and integrated care plans.

(c) 2016 Elsevier Ireland Ltd. All rights reserved.

\section{Introduction}

The proportion of people over the age of 65 years is dramatically rising worldwide. It has been estimated that more than $30 \%$ of Europeans will be over this age in 2050 . One consequence of longer life expectancy is the increased use of health care services. Although greater age does not necessarily imply poorer health, the heterogeneity of the intrinsic capacity varies enormously as a function of age between individuals.

\footnotetext{
* Corresponding author at: Emergency Department, Hospital Clínico San Carlos, Profesor Martín Lagos s/n, 28040 Madrid, Spain.

E-mail address: fjjms@hotmail.com (F.J. Martín-Sánchez).
}

Ultimately, the different levels of health in aging are better contemplated in terms of frailty, rather than years alive that are arbitrary and predominately centered on socio-demographic aspects [1].

Heart failure (HF) is a chronic disease. It has an incidence and prevalence that are highly age-dependent. Three out of 4 patients over the age of 75 years suffer with HF [2]. Acute HF (AHF) is a multi-organ dysfunction syndrome that involves cardiac, renal, pulmonary, cerebral, and hepatic injuries. It is one of the most frequent causes of visits to emergency departments (ED) and hospitalization [3,4]. Older patients with AHF require a more complex evaluation and have a worse shortterm prognosis across the spectrum of morbidity, cognitive and functional decline, and the risk of institutionalization and mortality, 
compared to younger adults [5,6]. Poorer outcomes in older individuals are probably more related to comorbidities, frailty and disability than with chronologic age [5].

The terms comorbidity, frailty and disability are associated with aging, and although commonly used interchangeably, they are unique entities with different prognoses and health care implications $[7,8]$ (Fig. 1).

Comorbidity describes a framework where one specific disease is the primary focus, and the other distinct entities are comorbid conditions modifying the course and the treatment of an individual with the index disease [9]. In HF patients, the prevalence of comorbidity has increased in the last 2 decades [10] and is associated with adverse events [11].

Disability is defined as difficulty or dependency in performing activities of daily living [7]. Functional disability is prevalent in HF [10], and the level of functional dependence determines a poor prognosis in older patients with AHF [12].

Frailty is clinically characterized by a reduction in physiological capacity not necessarily related to a specific disease process and typically involves alterations in multiple systems [13]. Frailty may be reversible or attenuated by interventions [13]. It is more frequent in patients with comorbidity and chronic diseases [10], particularly HF, than in the general population [14]. It is associated with higher risks of hospitalization, disability and mortality [15]. Approximately $50-70 \%$ of older patients admitted for AHF present with some degree of frailty [16-18]. This contributes to adverse short and long-term outcomes both in those managed medically and in relation to interventional procedures [18-19].

Therefore, evaluation of older patients with AHF requires more than an assessment of pump failure alone [20-24]. The identification of frailty and its degree is critical to improve prognosis and optimize the risk-benefit relationship of invasive diagnostic and therapeutic procedures. An evaluation of frailty is also necessary to accurately define older-person-centered and integrated care plans whose main goal is to maintain or reverse the potential decline in physical and cognitive capacities (add life to your years and not years to your life).

This position paper highlights the need to recognize that frailty, as a syndrome, is different from aging, comorbidity and disability. We will review the definition and diagnosis of frailty and will present a practical evaluation and management of it and other possible concurrent circumstances in older patients attended with AHF.

\section{Definitions of frailty}

\subsection{Concept}

Frailty is a dynamic and nonlinear process. It describes a state of vulnerability to stressors in terms of systems reserves and capacity of response to stress situations (i.e., decompensation of AHF) in older populations [13]. This concept may help to identify patients at increased risk of disability and/or other adverse health outcomes (i.e. death, reduced physical performance, functional decline, hospitalization or institutionalization) $[13,25]$.

\subsection{Models of frailty}

Two main models have been used to conceptualize frailty. These are based on different theoretical constructs: 1) a biologic syndrome model and 2) an accumulation of deficiencies model [26].

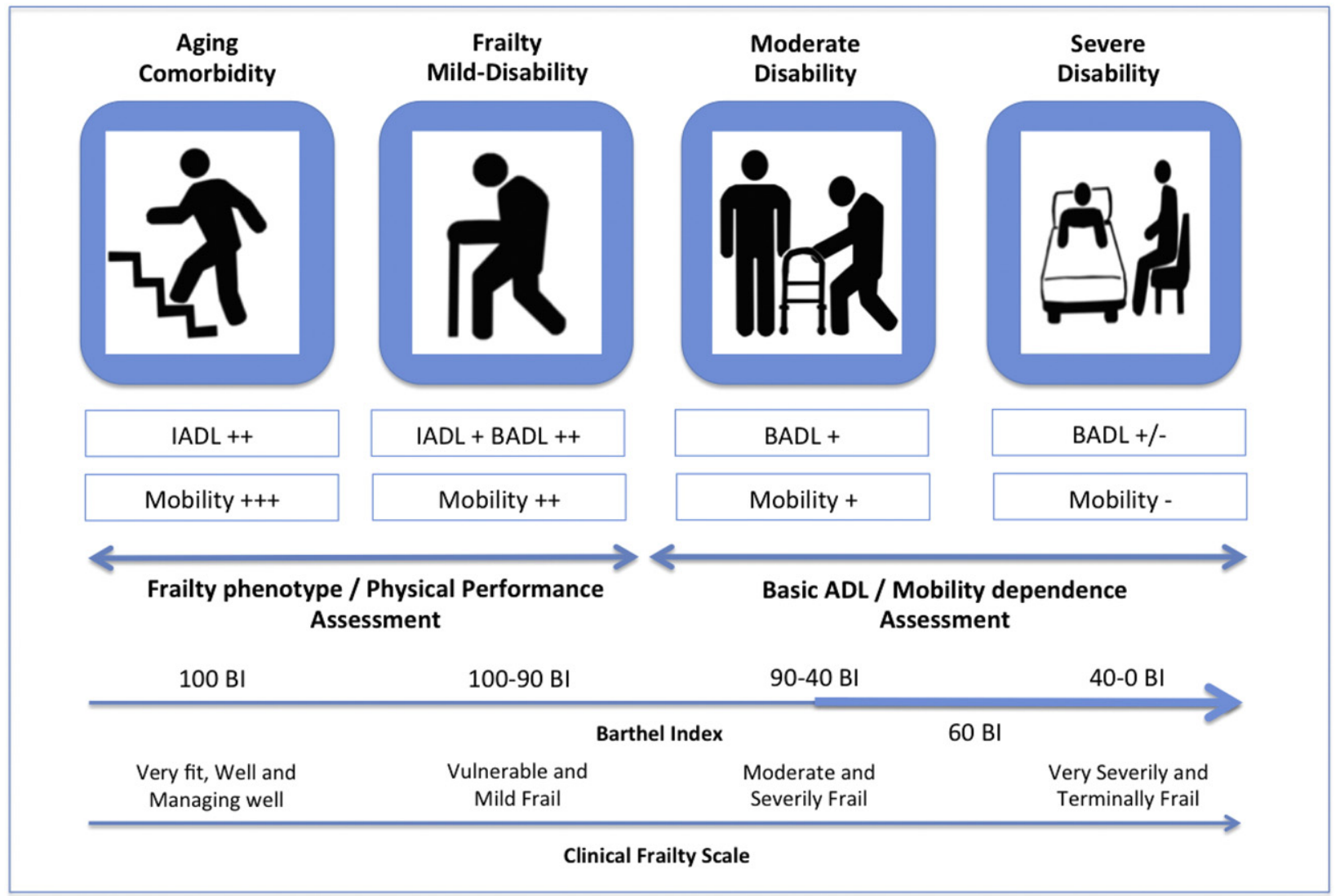

Instrumental activities of daily living (IADL): ability to use telephone, mode of transportation, ability to handle finances, responsibility for own medications, shopping, food preparation, housekeeping, laundry.

Basic activities of daily living (BADL): bathing, dressing, transferring, toileting, continence, and feeding.

Mobility: physical activity performed without help; requires a person, walking frame, or wheel chair; bedridden.

Fig. 1. Practical approach to assess the vulnerability in older patients with acute heart failure. 


\subsubsection{Frailty phenotype}

This model, based on data from the Cardiovascular Health Study, considers frailty as a biologic syndrome characterized by the presence of 3 or more of 5 components: 1) exhaustion, 2) unintentional weight loss, 3) impaired grip strength, 4) slowness, and 5) low physical activity [27] (Table 1). Subsequently, some authors have proposed variations of the original model by introducing new criteria (i.e. cognitive impairment) or even reducing the number of components required (i.e. slow gait speed, low physical activity and weight loss) [25,28].

\subsubsection{Frailty index (FI)}

This model, derived from the Canadian Study of Health and Aging, is based on deficit accumulation; that is, a measure of the cumulative burden of non-specified age-associated health deficits (i.e. diseases, impairments in cognition, mood, mobility, or function) associated with poor outcomes. The frailty index was originally comprised of 70 measures and conceptualized frailty as a continuum. This model counts disabilities and comorbidities and is able to quantitatively summarize vulnerability [29].

Numerous other frailty definitions have been developed, but have largely been based on these two basic conceptual approaches [30].

\section{Tools for identifying frailty in older patients with AHF}

\subsection{Screening of frailty in the emergency setting}

Several screening tools for frailty, based on a multi-domain approach, have been proposed [31]. The tools most frequently studied are the Identification of Seniors at Risk (ISAR) [32] and Triage Risk Screening Tool (TRST) [33]. Both are validated for older patients attending in the emergency department (ED). These are self-reported (or obtained by a nurse) questionnaires, take approximately 1 min to administer, and are composed of six items related to different domains. The score ranges from 0 to 6 ( $0=$ low risk, $6=$ high risk). A score of two or more is associated with a greater probability of presenting short- and long-term adverse outcomes (hospital readmission, ED revisit, and functional decline and mortality) [ 32,33]. These tools have a high sensitivity and relatively low specificity, although the predictive capacity for adverse outcomes of the ISAR seems better than that of the TRST [31]. Regarding the frailty syndrome, the ISAR has shown a good predictive capacity in identifying frail older patients in the ED [34].

The ISAR is considered a useful screening tool for frailty in older patients presenting to the ED [34] (Table S1 in the supplementary material). Taking into account its limitations [35], the use of the ISAR alone is inadequate and the cut-off of $\geq 2$ may be useful to select older patients most likely to benefit from geriatric assessment [34]. Some authors have suggested a higher cut-off point, or that consideration as a continuous variable, may facilitate more efficient use of care resources [31]. They suggest a cut-off of 3 as better in terms of discriminative capacity for adverse outcomes [36].

\subsection{Diagnosis of frailty in inpatient units}

Many tools have been developed to diagnose frailty in the older population with substantial differences in respect to their ability to predict adverse outcomes [37]. Nonetheless, the reliability and validity of these tools have rarely been evaluated [38]. The few studies in which they were tested were epidemiological and their application in the cardiovascular setting, and specifically in HF, is limited [39] (Table 2). Indeed, the best tool to determine frailty for use in research and clinical practice remains to be established [38]. Therefore, when selecting a frailty assessment tool, one must consider where it was validated (setting and population), the mode of administration in relation to time-consumption and personnel, and the specialized equipment required [38].

Most studies in HF are based on tools derived from the frailty phenotype (Fried Scale) or from some of its domains (Physical Performance Test) [40]. There is less evidence on accumulations of deficits instruments (i.e. Frailty Index-Comprehensive Geriatric Assessment (FICGA) or Tilburg Frailty Indicator (TFI)) in the cardiovascular setting [39,41] (Table 2).

The Fried Scale requires 3 or more criteria (exhaustion, unintentional weight loss, impaired strength, slowness, and low physical activity) for the diagnosis of physical frailty (Table 1) [27]. It is important to take into

Table 1

Fried criteria.

\begin{tabular}{|c|c|c|}
\hline & $\begin{array}{l}\text { Original frailty phenotype } \\
\text { (as proposed by Fried et al. 2001) }\end{array}$ & Self-reported deficit \\
\hline Exhaustion & $\begin{array}{l}\text { How often in the last week did you feel this way? (a) I felt that } \\
\text { everything I did was an effort; (b) I could not get going } \\
\text { A moderate amount of the time ( } 3-4 \text { days) or most of the time }=1 \text {; } \\
\text { rarely or none of the time ( }<1 \text { day) or some or a little of the time }(1-2 \text { days })=0\end{array}$ & $\begin{array}{l}\text { Self-report of fatigue or felt unusually tired or } \\
\text { weak in the past month. }\end{array}$ \\
\hline Weight loss & $\begin{array}{l}\text { In the last year, have you lost more than } 5 \mathrm{~kg} \text { unintentionally } \\
\text { (i.e., not due to dieting or exercise)? yes }=1, \text { no }=0\end{array}$ & $\begin{array}{l}\text { Self-report weight loss }>5 \mathrm{~kg} \text { unintentionally } \\
\text { in the past year. }\end{array}$ \\
\hline Physical activity & $\begin{array}{l}\text { Minnesota Leisure Time Activity Questionnaire (past } 2 \text { weeks): } \\
\text { walking, chores (moderately strenuous), mowing the lawn, raking, } \\
\text { gardening, hiking, jogging, biking, exercise cycling, dancing, aerobics, } \\
\text { bowling, golf, singles tennis, doubles tennis, racquetball, calisthenics, } \\
\text { swimming. Deficit given to (adjusted by sex) } \\
\text {-Men: kcals/week }<383 \text {; } \\
\text {-Women: kcals/week }<270\end{array}$ & $\begin{array}{l}\text { Self-report frequency and duration of } \\
\text { physical activities. }\end{array}$ \\
\hline Grip strength & $\begin{array}{l}\text { Average grip strength score in dominant hand ( } 3 \text { trials) using a JAMAR hand } \\
\text { held dynamometer. Deficit given to (adjusted by sex and BMI quartile based } \\
\text { on CHS population by Fried et al.) } \\
\text {-Men: BMI } \leq 24 \mathrm{~kg} \text { and strength }<29 \mathrm{~kg} \text {; BMI } 24.1-26 \mathrm{~kg} \text { and strength }<30 \mathrm{~kg} \text {; } \\
\text { men: BMI } 26.1-28 \mathrm{~kg} \text { and strength }<30 \mathrm{~kg} \text {; BMI } 24.1-26 \mathrm{~kg} \text { and } \\
\text { strength }<30 \mathrm{~kg} \text {; BMI }>28 \mathrm{~kg} \text { and strength }<32 \mathrm{~kg} \\
\text {-Women: BMI } \leq 23 \mathrm{~kg} \text { and strength }<17 \mathrm{~kg} \text {; BMI } 23.1-26 \mathrm{~kg} \text { and } \\
\text { strength }<17.3 \mathrm{~kg} \text {; men: BMI } 26.1-29 \mathrm{~kg} \text { and strength }<18 \mathrm{~kg} \text {; BMI }>29 \text { and strength }<21 \mathrm{~kg}\end{array}$ & Self-report of difficulty standing up from a chair. \\
\hline Walking time & $\begin{array}{l}\text { Walking speed score ( } 15 \mathrm{ft} \text {. }(5 \mathrm{~m} \text { ) test, usual pace, one trial) } \\
\text { Deficit given to (adjusted by sex and median height based on CHS population by Fried et al.) } \\
\text {-Men: height } \leq 173 \mathrm{~cm} \text { and speed } \leq 0.6531 \mathrm{~m} / \mathrm{s} \text {; height }>173 \mathrm{~cm} \text { and speed } \leq 0.762 \mathrm{~m} / \mathrm{s} \\
\text {-Women: height } \leq 159 \mathrm{~cm} \text { and speed } \leq 0.6531 \mathrm{~m} / \mathrm{s} \text {; height }>159 \mathrm{~cm} \text { and speed } \leq 0.762 \mathrm{~m} / \mathrm{s}\end{array}$ & Self-report of any difficulty for walking $100 \mathrm{~m}$. \\
\hline
\end{tabular}

5 items: 0 deficits: nonfrail; $1-2$ deficits: prefrail; $\geq 3$ deficits: frail. 
Table 2

Principal studies about frailty in older patients with acute heart failure.

\begin{tabular}{|c|c|c|c|c|c|c|}
\hline Setting & Items & Score (cut-off) & Administer & Domains & Subjects & Outcomes \\
\hline $\begin{array}{l}\text { Emergency department } \\
\text { ISAR } \\
\text { Identification } \\
\text { Seniors at Risk } \\
\text { McClusker (1999) }\end{array}$ & 6 & $\begin{array}{l}0-6 \\
(\geq 2=\text { frailty })\end{array}$ & Self-reported & $\begin{array}{l}\text { Cognition, ADL, medications, } \\
\text { vision, recent hospitalization }\end{array}$ & $\begin{array}{l}\text { Patients } \geq 65 \text { years } \\
\text { discharged from ED }\end{array}$ & $\begin{array}{l}\text { 30-Day mortality } \\
\text { 30-Day hospital readmission } \\
\text { 30-Day functional decline }\end{array}$ \\
\hline $\begin{array}{l}\text { Inpatients unit } \\
\text { SPPB } \\
\text { Short Physical } \\
\text { Performance Battery } \\
\text { Volpato }(2008,2011) \\
\text { Chiarantini }(2010)\end{array}$ & 3 & $\begin{array}{l}0-12 \\
(<5=\text { frailty })\end{array}$ & Physical performance & $\begin{array}{l}5 \text {-m gait speed test } \\
\text { Chair rise test } \\
\text { Balance test }\end{array}$ & $\begin{array}{l}\text { Patients } \geq 65 \text { years } \\
\text { admitted for AHF }\end{array}$ & $\begin{array}{l}\text { Length of stay } \\
\text { Incident disability } \\
\text { 15-Month mortality }\end{array}$ \\
\hline $\begin{array}{l}\text { TFI } \\
\text { Tilburg Frailty Indicator } \\
\text { Uchmanowicz I (2015) }\end{array}$ & 15 & $\begin{array}{l}0-15 \\
(\geq 5=\text { frailty })\end{array}$ & Self-reported & $\begin{array}{l}\text { Physical ( } 8 \text { ), psychological } \\
(4), \text { social (3). }\end{array}$ & $\begin{array}{l}\text { Patients } \geq 60 \text { years } \\
\text { admitted for AHF }\end{array}$ & $\begin{array}{l}\text { Self-care capabilities } \\
\text { Health-related quality of life }\end{array}$ \\
\hline $\begin{array}{l}\text { MPI } \\
\text { Multi prognostic index } \\
\text { Pilotto }(2010)\end{array}$ & 63 & $\begin{array}{l}0-1 \\
(0.34-0.66=\text { moderate risk; } \\
0.67-1=\text { high risk })\end{array}$ & $\begin{array}{l}\text { Data abstracted out of } \\
\text { CGA by geriatrician }\end{array}$ & $\begin{array}{l}\text { Cognition, ADL, nutrition, } \\
\text { comorbidities, medications, } \\
\text { decubitus, social support }\end{array}$ & $\begin{array}{l}\text { Patients } \geq 65 \text { years } \\
\text { admitted for AHF }\end{array}$ & 1-Month mortality \\
\hline $\begin{array}{l}\text { CGA Score } \\
\text { Rodriguez Pascual } \\
(2012,2014)\end{array}$ & 5 & $\begin{array}{l}0-10 \\
(\leq 2: \text { lower risk; } 3-4 ; \\
5-6 ; \geq 7: \text { higher risk) }\end{array}$ & $\begin{array}{l}\text { Data abstracted out of } \\
\text { CGA by geriatrician }\end{array}$ & $\begin{array}{l}\text { Cognition, ADL, mobility, } \\
\text { comorbidity, medications }\end{array}$ & $\begin{array}{l}\text { Patients } \geq 75 \text { years } \\
\text { admitted for AHF }\end{array}$ & $\begin{array}{l}\text { In-hospital mortality } \\
\text { 2-Year mortality }\end{array}$ \\
\hline
\end{tabular}

IADL: instrumental activities of daily living.

account that any modification from the original scale proposed by Fried et al. in 2001 may influence the results. In order to compare the different studies available using the frailty phenotype, minimum requirements of the measurements must be reported [42].

Several Physical Performance tests have been described, including the Short Physical Performance Battery, gait or walking speed, timed-upand-go test, handgrip strength, and 4 or 6 -minute walk test, each of which may identify physical frailty or preclinical disability in the older population [43].

The Short Physical Performance Battery (SPPB) encompasses slowness, weakness, and balance. This test assesses lower extremity function using three physical performance tests that include standing balance (the ability to stand with the feet together in the side-by-side, semitandem, and tandem positions), gait speed (time to walk $8 \mathrm{ft}$ or $2.4 \mathrm{~m}$ ), and strength and endurance (time to rise from a chair and return to the seated position 5 times). The total score ranges from 0 to 12 , with higher scores indicating better performance [44]. The SPPB predicts incident activities of daily living disability, worsening mobility and death in older community HF subjects [45] (Fig. 2).

Gait speed is a part of the SPPB, but as a single parameter it has been associated with survival in older adults [46]. It is an important risk factor for 1-year mortality in an older community population with HF [47]. The 5 -m distance is a good balance between the walking speed achieved and cardiopulmonary limitations [39].

Alternatively, the timed get-up-and-go test measures the time needed to complete a series of functionally important tasks such as standing up from a chair, walking a short distance, turning around, returning to the chair, and sitting down again [48]. This test appears to be a reliable and valid functional measurement in patients with HF [49]. A gait speed $<0.8 \mathrm{~m} / \mathrm{s}$ and a timed-up-and-go test $>10 \mathrm{~s}$ are markers of possible frailty in community-dwelling older patients [50]. In patients with lower limb conditions, the handgrip test may be an alternative option [51].

The SPPB is easily applied, preferable to other performance tests (i.e. 4-m walk test, 6-minute walk test, and handgrip strength) in community-dwelling older patients with HF [45], and it is currently considered the best instrument to characterize frailty in clinical trials [52]. In older patients with HF, a total SPPB score $\leq 4$ applied at hospital admission is an independent predictor of the length of hospital stay [53]. Further, its measurement at hospital discharge is an independent predictor of 30-day mortality [54] and rehospitalization [55].
Comprehensive Geriatric Assessment (CGA) is the instrument recommended for the evaluation and care of frail older patients in clinical practice [56]. This holistic evaluation is performed by a multidisciplinary team that usually includes a geriatrician or other physicians knowledgeable in the care of older adults, a nurse, social worker, pharmacist, and an occupational or physical therapist. This team assesses comorbidity, polypharmacy, and cognitive, functional, nutritional, and socioeconomic areas in order to develop treatment planning and follow-up. The main limitations of the CGA include the need to have experts of diverse disciplines and enough time for the evaluation. The CGA has demonstrated ability to predict in-hospital and long-term adverse outcomes in older patients admitted with HF [57-60]. Major geriatric syndromes (frailty, severe disability, cognitive decline, and depression) are associated with poor intra-hospital and 1-year results in older patients with acute cardiac conditions [58]. The CGA is currently the gold standard to detect frailty and should be used when making complex decisions regarding invasive procedures. Because of the limitations mentioned above, some authors have proposed a Brief Geriatric Assessment adapted to non-geriatricians using a combination of screening scales that approach different domains of the patient [61] (Table 3).

Various instruments derived from CGA have been published (i.e. Multidimensional Prognostic Index [MPI], CGA score, and Edmonton Frail Scale [EFS]) that have a high predictive value of adverse short-term results. The MPI predicts the 1-month mortality in patients aged 65 years and older admitted with AHF [57]. The CGA score estimates the inhospital and 2-year mortality in older patients hospitalized for AHF $[59,60]$. The EFS tool may be useful to identify frailty when considering a surgical intervention in order to help with pre-operative optimization [50].

With regard to the last-mentioned instrument derived from CGA, EFS is a brief multidimensional tool that may be applied in older admitted patients by non-geriatricians. It includes the domains of cognition, mood, mobility, functional independence, drugs, social support, nutrition, health attitudes, continence, medical disease load and quality of life [62]. The examination takes less than $5 \mathrm{~min}$ and the maximum score (total 17) represents the highest level of frailty [62]. The new version of this scale, the Reported Edmonton Frail Scale (REFS), adapted from the EFS, substitutes the get up and go test with self-reporting of physical function before the current illness. The REFS is scored from 1 to 18 [63]. With respect to the need for major cardiac interventional or surgical decisions in invasive cardiovascular procedures, recent 


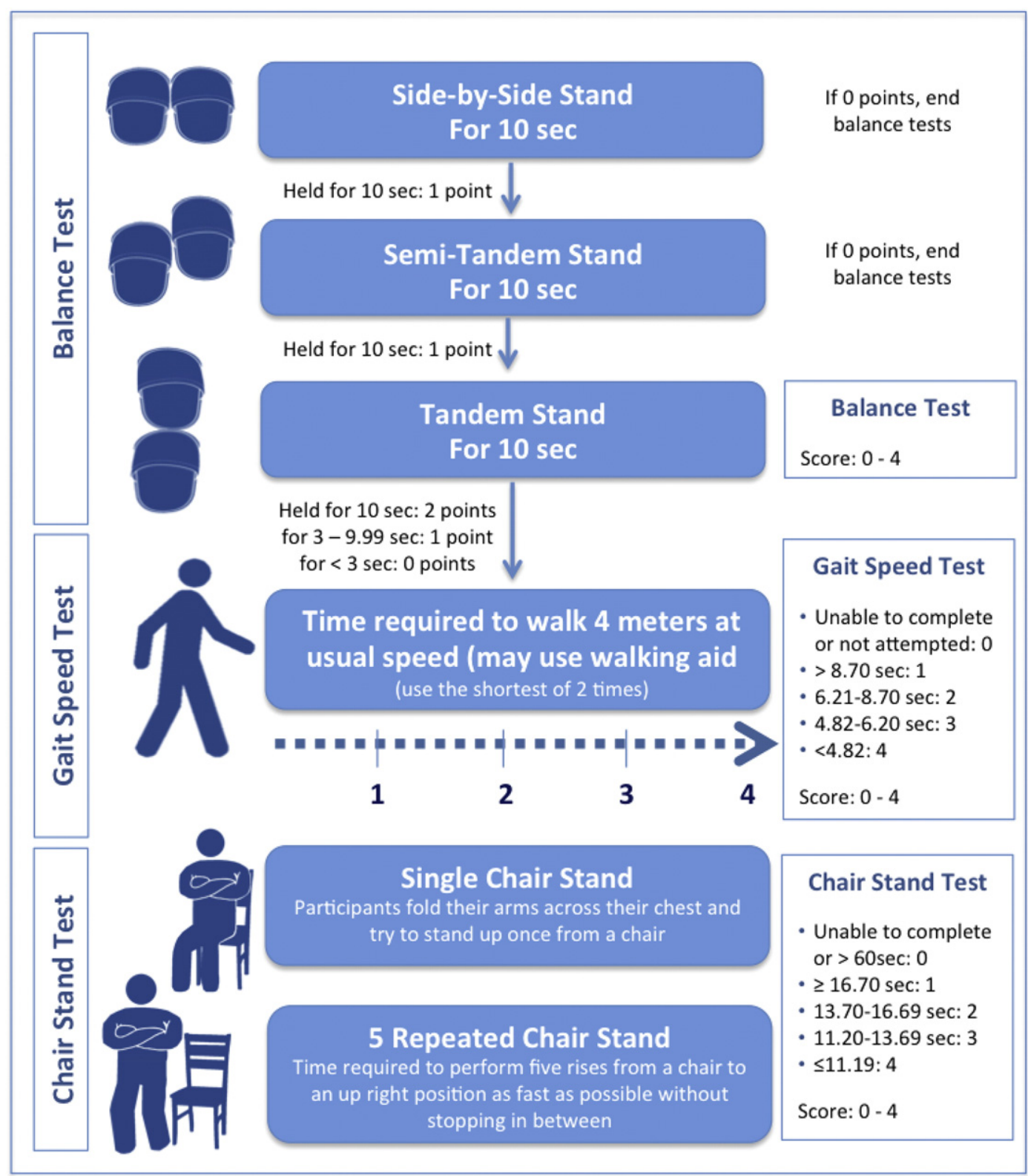

Fig. 2. Short Physical Performance Battery. *See the videos in the supplementary electronic material.

findings have shown that poor agreement among clinicians when using the REFS to diagnose frailty, and therefore a geriatric assessment is recommended in these cases [64].

Table 3

Brief geriatric assessment based on comprehensive geriatric assessment.

\begin{tabular}{ll}
\hline Domain & Tool \\
\hline Cognitive & Montreal Cognitive Assessment (MOCA) \\
Depression & 5-item Geriatric Depression Scale (5-GDS) \\
Functional & Lawton index (LI) (8 instrumental activities of daily living) \\
& Barthel index (BI) (8 basic activities of daily living \\
& and 2 of mobility). \\
Nutrition & Mini-Nutritional Status - Short Form (MNA-SF) \\
& Serum albumin \\
Polypharmacy & START and STOPP Criteria \\
Comorbidity & Charlson Comorbidity Index \\
Hearing & Whispering test \\
Visual & Snellen test \\
Socio-economic & Gijon's social-familial evaluation scale (SFES) \\
\hline
\end{tabular}

\section{Evaluation of frailty in older patients with AHF}

In all older patients presenting with AHF, the level of frailty must be determined through assessment and monitoring of physical and cognitive status during acute management, during convalescence and, above all, at the time of hospital discharge [50]. Some circumstances, such as clinical presentation (i.e. delirium, falls or acute functional decline) or the presence of some level of baseline functional dependence on the basic activities of daily living, may be used to indicate possible frailty [50]. Biomarkers are only able to capture single aspects of frailty and are weakly associated with clinically meaningful outcomes [65]. In the absence of universal recommendation as to how to detect vulnerable older patients in clinical practice, we suggest a simplistic approach in the ED and ward settings (Fig. 3).

\subsection{Emergency setting}

In the ED, where personnel and time resources are limited, we recommend to screen for frailty, particularly in patients with non- 
apparent disability discharged directly from the ED. We recommend using ISAR as a continuous variable, with a cut point $\geq 2$ for maximum sensitivity and $\geq 3$ for maximum discrimination, to provide an individualized care plan that includes a CGA program.

\subsection{Inpatient units}

On inpatient units, we recommend that information about comorbidity (Charlson Comorbidity Index) (Table S2 in the supplementary material) [66] and baseline functional status (Barthel Index) (Table S3 in the supplementary material) [67], be collected at admission to establish the grade of disability.

In older patients with established disability (moderate and severe disability), measurement of physical frailty should be focused on basic activities of daily living and mobility. The Barthel Index has shown a greater sensitivity to change and may detect the onset of disability earlier than other scores [8] (Table). Previous studies have shown that severe baseline functional dependence (Barthel Index $<60$ points) in older patients attended with AHF is associated with an increase in 30-day mortality [12], and its inclusion in the HF risk stratification models (Bi-EFFECT) has improved the prediction of 30-day mortality [68]. In this profile patient's information about other domains (e.g., comorbidity, medications, cognitive, nutritional and social support) should be included since these variables influence shortand long-term prognoses, and care planning decisions [58-60].

We recommend using instruments based on the frailty phenotype (i.e. the Fried Scale) or physical performance (i.e. SPPB) to diagnose physical frailty in older patients with non-established disability (pre-disabled or mild disability) [69]. The presence of frailty is associated with in-hospital, as well as short and long-term outcomes [53-55]. As mentioned above, there is no single feasible, valid tool to diagnose frailty in AHF inpatients and neither has the best time to perform these tests been established. Multi-domain tools do not necessarily provide incremental value above single-domain tools, and the ease of implementation may be an important factor for adoption. Taking into account the acute phase of the heart failure condition, self-reported instruments may be more appropriate at hospital admission, while objective performance measures would be better suited at hospital discharge. Finally, some authors have also suggested the addition of cognitive and nutritional status to improve the diagnosis of frailty [13].

It is also important to monitor the cognitive and functional situation during hospitalization since delirium and acute functional decline are markers of frailty [50]. Delirium is the main manifestation of cognitive frailty and frequently appears in hospitalized elderly patients with cognitive impairment. Its presence in patients with decompensated HF has been associated with 30-day mortality [70]. The Confusion Assessment Method (CAM) is a good tool for the identification of delirium [71]. The CAM for the Intensive Care Unit (CAM-ICU) [72] has shown to have a better capacity to diagnose delirium in older patients in the ED [73]. It is recommended that cognitive status is evaluated, after rulingout delirium, at the time of the first visit, or failing that, on ward admission. Montreal Cognitive Assessment (MoCA) is the best method to screen for cognitive impairment in patients with $\mathrm{HF}[74,75]$ in both clinical practice and trials [52].

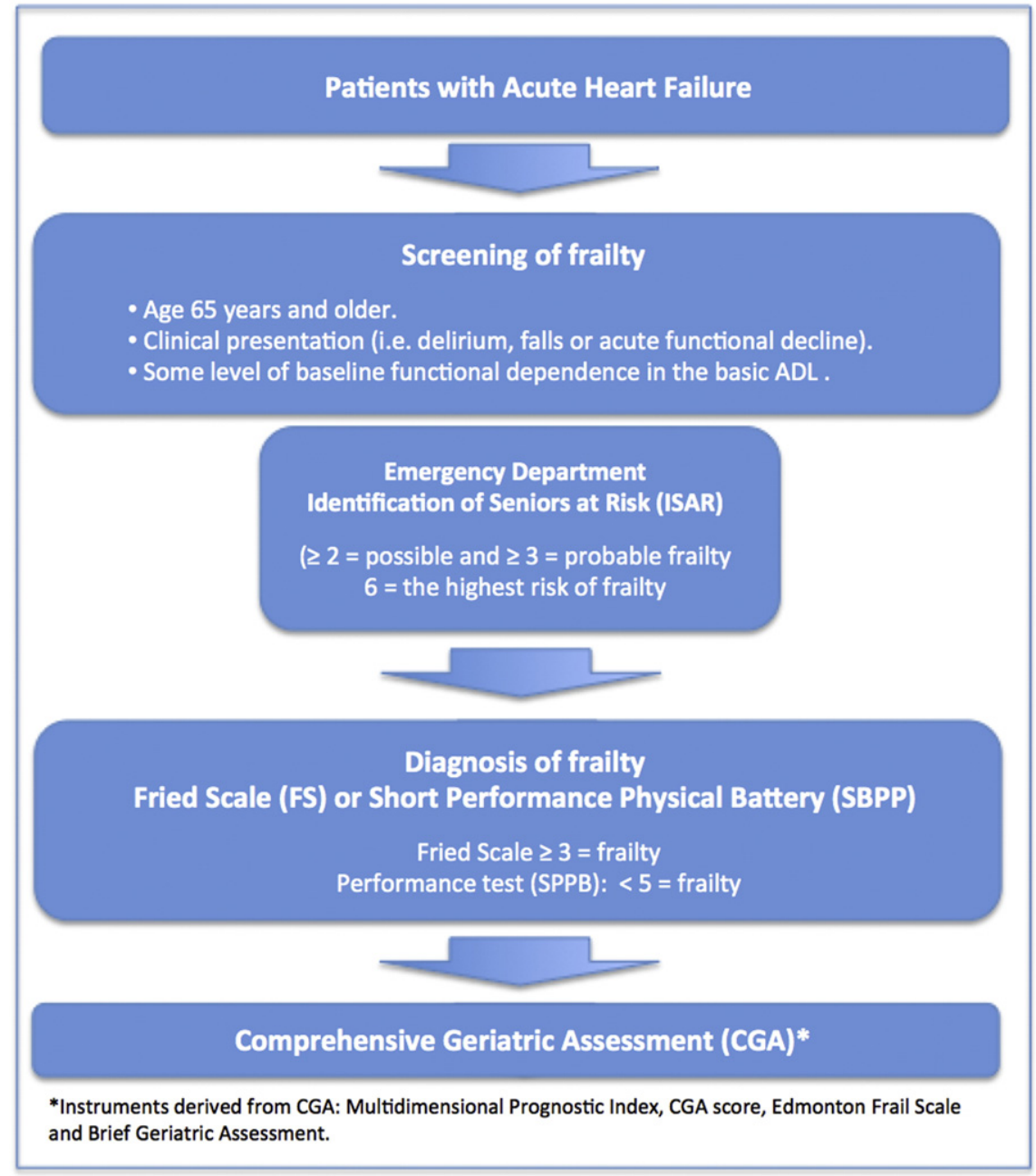

Fig. 3. Approach to assess the frailty in older patients with acute heart failure. 


\section{Frailty-based management in older patients with AHF}

The management of older patients with AHF should be based on clinical guidelines taking into account that older patients, and particularly frail older patients, have often been excluded from clinical trials $[76,77]$. We recommend the measurement of the degree of frailty as well as the documentation of the presence or absence of concurrent comorbidity and disability (Fig. 4).

The identification of frailty involves early treatment of the frailty syndrome and close monitoring of patient capacities during and after hospitalization in order to minimize disability. The most commonly used interventions to treat frailty include, comorbidity optimization, exercise, protein-calorie supplementation, and the development of an individualized care and support plan based on a CGA [50,59]. Regarding vitamin D3, it was not demonstrated to improve physical performance in spite of the increase in serum 250HD in older patients with HF [78]. These interventions can reverse frailty, but may have no effect on adverse outcomes (hospitalizations, falls, or performance of activities of daily living) in community-living older persons [79]. The presence of significant functional decline or delirium in non-disabled older patients with AHF should be considered as a high-risk situation that needs CGA. Frailty should be determined with the currently used risk models for decision making. Regarding invasive procedures, the identification of frailty, using frailty criteria [80-84] and performance tests (i.e. 5 m-gait speed $[85,86]$ and the timed-get up-and-go test [87]) has helped to predict short- and long-term adverse events in patients undergoing transcatheter aortic valve replacement [80,82], cardiac surgery [83], cardiac resynchronization therapy [84] and post percutaneus coronary interventions [81].

The presence of comorbidities and renal failure may make clinical (i.e. chronic obstructive pulmonary disease (COPD)) [88] and biochemical (i.e. renal failure) [89] diagnosis of AHF even more difficult in frail older patients. Some comorbidities such as anemia, renal failure and hyperglycaemia, may influence the short and long-term prognoses [90-93]. The treatment of concurrent conditions in the frail older patients with AHF should be optimized by balancing the risk-benefit relation (prioritizations, interactions or contraindications) and making adjustments according to creatinine clearance (MDRD-4). Polypharmacy should be minimized because of the increased risk of adverse events and the consequence of potentially reduced adherence. The application of evidencebased medication review checklists (e.g. STOPP/START criteria) can be helpful to reduce inappropriate medicine use [50]. Regarding heath care, multi-provider or multi-settings should be avoided, or failing this, they should be well coordinated, with close monitoring of active morbidities during both hospitalization and after discharge.

Disabled patients represent the highest risk scenario and require more complex decision-making regarding treatment and care planning. One out of three patients aged 85 years and older (one of six if $\geq 75$ years) attending with AHF in the ED has a moderate or severe disability [5]. To facilitate the determination of frailty, we suggest distinguishing between patients with middle or moderate and severe disability. In moderate disability there may be a thin line dividing

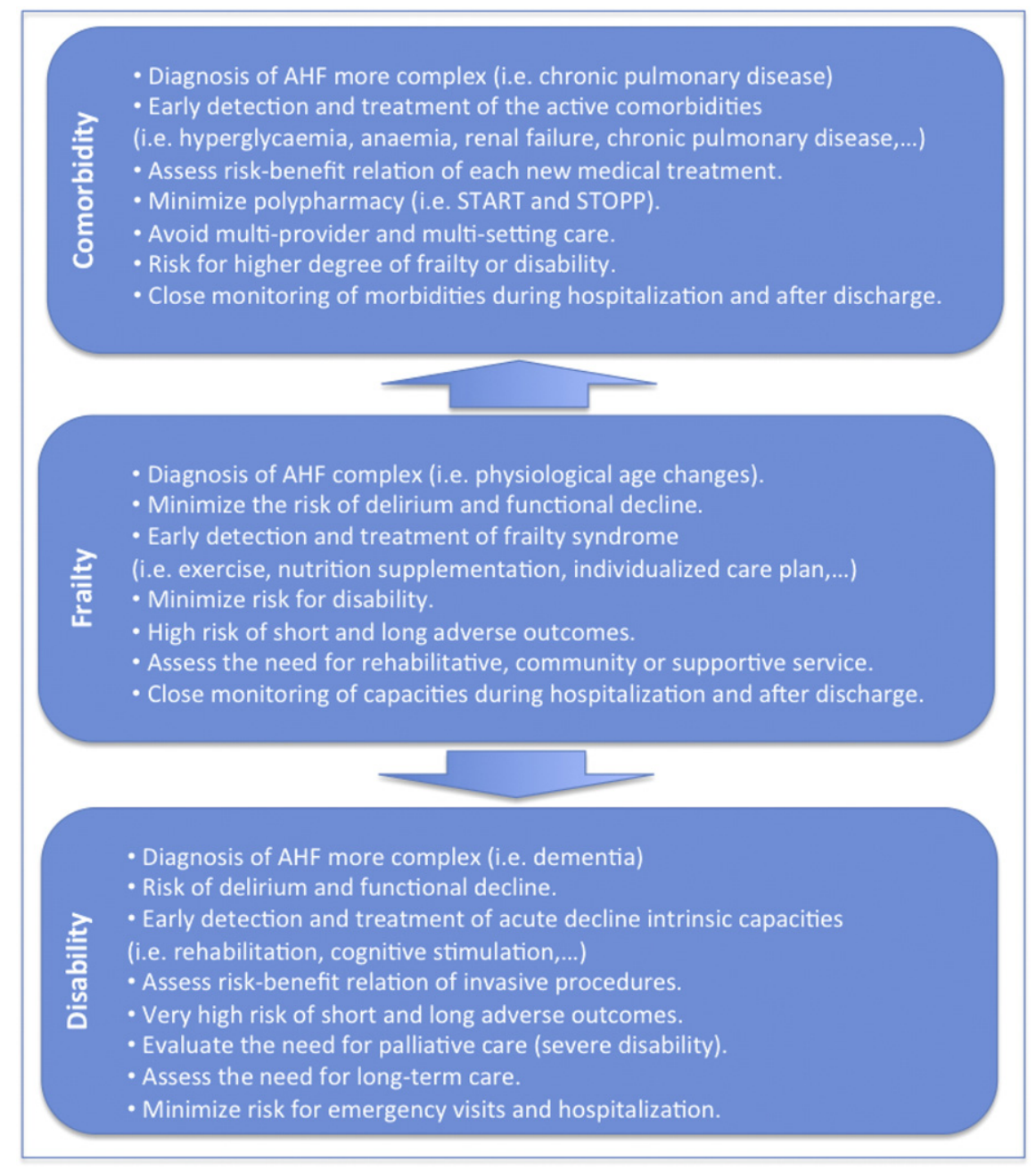

Fig. 4. Management of older patients with acute heart failure based on frailty. 
consideration for therapeutic invasive procedures and their indications (Barthel Index 90-40 points). These decisions should be based on CGA integrating risk scores, and frailty and disability components.

Palliative care, ethical constructs, advanced directives, and the rationalization of medications should be considered in patients with nonacute severe disability. There is no evidence to guide end-of-life decisions for older patients with HF. The usual medications such as beta-blockers, diuretics, angiotensin-converting enzyme inhibitors, angiotensin receptor blockers, nitroglycerin and digoxin are recommended to maintain symptom relief and improve quality of life [94]. Other treatments such as lipid-lowering medications and antiplatelet agents, with the exception of aspirin, may never be indicated and anticoagulants and antiarrhythmics may rarely be appropriate [95].

Regarding the transition of care, the discharge of all frail older patients with AHF should include a comprehensive care and support plan. This should involve plans for optimization and maintenance, self-care, escalation (what to look for and who to call), and emergency responses that may include whether or not hospital care is appropriate/desirable and what alternatives are in place [50]. All these aspects are important in order to improve subjective and objective quality of life in older patients with AHF [96].

\section{Conclusions}

In conclusion, 1) AHF is a multi-organ dysfunction syndrome. In addition to cardiac, renal, pulmonary, cerebral, and hepatic injuries, as well as non-cardiac comorbidity, frailty and disability are independent factors predicting mortality, morbidity, cognitive and functional decline, and the risk of institutionalization in older patients with AHF; 2) frailty (or state of vulnerability to stressors) is a treatable and potentially reversible syndrome which increases the risk of disability and/or other adverse health outcomes; 3 ) frailty identification is critical in older patients with AHF in order to improve the stratification of prognosis (disposition), the evaluation of the risk-benefits of invasive diagnostic and therapeutic procedures and the development of older-person-centered and integrated care plans (person-centered coordinated care) which have the main goal of maintaining or reversing potential declines in physical and cognitive capacities; 4) though the best tool to determine frailty for use in research and clinical practice remains to be established, we recommend the ISAR for the screening of frailty in ED, and the Fried phenotype (i.e. Fried Scale) and Physical Performance Test (i.e. SPPB) for the diagnosis of frailty during the hospitalization of older patients with AHF; 5) CGA (or instruments derived from CGA) is the instrument recommended for the evaluation and care of frail older patients in clinical practice.

Supplementary data to this article can be found online at http://dx. doi.org/10.1016/j.ijcard.2016.07.151.

\section{Conflict of interest}

FJMS received advisory/consulting fees from Novartis. MC reports a research grant from Roche Diagnostics as well as speaker's/consulting honoraria from Roche Diagnostics, Novartis, MSD, Alere, MSD, Boehringer Ingelheim, Pfizer, and Philips. OM received advisory/consulting fees from Novartis and The Medicines Company; as well as research funding from Bayer Health Care, Thermofisher, Novartis, and Orion-Pharma. WFP reports research grants from: Abbott, Alere, Cardiorentis, Roche, and The Medicines Company. He reports the following consultancies: Alere, Cardiorentis, and ZS Pharma. He acknowledges the following ownership interests: Emergencies in Medicine, LLC, and Comprehensive Research Associates. HB received research grants from AstraZeneca and advisory/speaker's fees from Abbott, AstraZeneca, Bayer, BMS, Daiichi Sankyo, Eli Lilly, Menarini, Novartis, Pfizer, Sanofi and Servier. LC has received research grants from the Queensland Emergency Research Foundation, Abbott, ALERE, Radiometer Pacific, Roche, Siemens, and the Royal Brisbane and Women's
Foundation, as well as speaker's/consulting honoraria or travel support from Abbott, ALERE, Astra Zeneca, Boehringer Ingelheim, Novartis, Radiometer Pacific, Roche, and Siemens. SDS is a consultant for Novartis, Cardiorentis, Alere and Thermofisher. EP has received research grants from the National Institutes of Health/National Heart, Lung, and Blood Institute and the American Heart Association, as well as consulting honoraria from Sanofi and Parexel. CM has received research grants from the Swiss National Science Foundation and the Swiss Heart Foundation, the European Union, the Cardiovascular Research Foundation Basel, 8sense, Abbott, ALERE, Biomerieux, Brahms, Critical Diagnostics, Roche, Siemens, Singulex, and the University Hospital Basel, as well as speaker's/consulting honoraria or travel support from Abbott, ALERE, Astra Zeneca, Bayer, Biomerieux, BMS, Brahms, Cardiorentis, Daiichi Sankyo, Eli-Lilly, Novartis, Roche, Siemens, and Singulex. The rest of the authors do not have any conflict of interests to declare.

\section{Acknowledgements}

This study was partially supported by grants coming from Instituto de Salud Carlos III supported with funds from Spanish Ministry of Health and FEDER (PI15/00773, PI15/01019, and PI11/01021), La Marató de TV3 (2015), and the National Institutes of Health/National Heart, Lung, and Blood Institute (1-K23-HL123533-01A1). Manuel Cañadas Fernández has illustrated this manuscript.

\section{References}

[1] World Health Organization, World Report on Ageing and Health, 2015.

[2] P. Llorens, R. Escoda, O. Miró, P. Herrero Puente, F.J. Martín-Sánchez, J. Jacob, et al., Characteristics and clinical course of patients with acute heart failure and the therapeutic measures applied in Spanish emergency departments: based on the EAHFE registry (Epidemiology of Acute Heart Failure in Emergency Departments), Emergencias 27 (2015) 11-22.

[3] A.S. Go, D. Mozaffarian, V.L. Roger, E.J. Benjamin, J.D. Berry, M.J. Blaha, et al., Heart disease and stroke statistics - 2014 update: a report from the American Heart Association, Circulation 129 (2014) e28-e292.

[4] P.A. Heidenreich, N.M. Albert, L.A. Allen, D.A. Bluemke, J. Butler, G.C. Fonarow, et al., Forecasting the impact of heart failure in the United States: a policy statement from the American Heart Association, Circ. Heart Fail. 6 (2013) 606-619.

[5] F.J. Martín-Sánchez, R. Marino-Genicio, E. Rodríguez-Adrada, J. Jacob, P. Herrero, O. Miró, et al., Management of acute heart failure in Spanish emergency departments based on age, Rev. Esp. Cardiol. 66 (2013) 715-720.

[6] A. Teixeira, J. Parenica, J.J. Park, S. Ishihara, K.F. AlHabib, S. Laribi, et al., Clinical presentation and outcome by age categories in acute heart failure: results from an international observational cohort, Eur. J. Heart Fail. 17 (2015) 1114-1123.

[7] L.P. Fried, L. Ferrucci, J. Darer, J.D. Williamson, G. Anderson, Untangling the concepts of disability, frailty and comorbidity: implications for improved targeting and care, J. Gerontol. A Biol. Sci. Med. Sci. 59 (2004) 255-263.

[8] P. Abizanda, L. Romero, P.M. Sanchez-Jurado, M. Martinez-Reig L Gomez-Arnedo, S.A. Alfonso, Frailty and mortality, disability and mobility loss in a Spanish cohort of older adults: the FRADEA study, Maturitas 74 (2013) 54-60.

[9] C.M. Boyd, C.S. Ritchie, E.F. Tipton, S.A. Studenski, D. Wieland, From bedside to bench: summary from the American Geriatrics Society/National Institute on Aging Research Conference on Comorbidity and Multiple Morbidity in Older Adults, Aging Clin. Exp. Res. 20 (2008) 181-188.

[10] C.Y. Wong, S.I. Chaudhry, M.M. Desai, H.M. Krumholz, Trends in comorbidity, disability, and polypharmacy in heart failure, Am. J. Med. 124 (2011) 136-143.

[11] C.A. Rushton, D.K. Satchithananda, P.W. Jones, U.T. Kadam, Non-cardiovascular comorbidity, severity and prognosis in non-selected heart failure populations: a systematic review and meta-analysis, Int. J. Cardiol. 196 (2015) 98-106

[12] O. Miro, P. Llorens, F.J. Martin-Sanchez, P. Herrero, J. Pavon, M.J. Perez-Dura, et al., Short-term prognostic factors in elderly patients seen in emergency departments for acute heart failure, Rev. Esp. Cardiol. 62 (2009) 757-764.

[13] L. Rodriguez-Mañas, C. Feart, G. Mann, J. Viña, S. Chatterji, W. Chodzko-Zajko, et al., Searching for an operational definition of frailty: a Delphi method based consensus statement: the Frailty Operative Definition-Consensus Conference project, J. Gerontol. A Biol. Sci. Med. Sci. 68 (2013) 62-67.

[14] S. Altimir, J. Lupón, B. González, M. Prats, T. Parajón, A. Urrutia, et al., Sex and age differences in fragility in a heart failure population, Eur. J. Heart Fail. 7 (2005) 798-802.

[15] S.M. McNallan, A.M. Chamberlain, Y. Gerber, M. Singh, R.L. Kane, S.A. Weston, et al., Measuring frailty in heart failure: a community perspective, Am. Heart J. 166 (2013) 768-774.

[16] D. Chiarantini, S. Volpato, F. Sioulis, et al., Lower extremity performance measures predict long-term prognosis in older patients hospitalized for heart failure, J. Card. Fail. 16 (2010) 390-395.

[17] M.T. Vidán, E. Sánchez, F. Fernández-Avilés, J.A. Serra-Rexach, J. Ortiz, H. Bueno, FRAIL-HF, a study to evaluate the clinical complexity of heart failure in 
nondependent older patients: rationale, methods and baseline characteristics, Clin. Cardiol. 37 (2014) 725-732.

[18] M.T. Vidán, V. Blaya-Novakova, E. Sánchez, J. Ortiz, J.A. Serra-Rexach, H. Bueno, Eur. J. Heart Fail. (2016), http://dx.doi.org/10.1002/ejhf.518.

[19] S.I. Chaudhry, G. McAvay, Y. Ning, H.G. Allore, A.B. Newman, T.M. Gill, Risk factors for onset of disability among older persons newly diagnosed with heart failure: the Cardiovascular Health Study, J. Card. Fail. 17 (2011) 764-770.

[20] J.J. McMurray, S. Adamopoulos, S.D. Anker, A. Auricchio, M. Böhm, K. Dickstein, et al., ESC guidelines for the diagnosis and treatment of acute and chronic heart failure 2012: the Task Force for the Diagnosis and Treatment of Acute and Chronic Heart Failure 2012 of the European Society of Cardiology. Developed in collaboration with the Heart Failure Association (HFA) of the ESC, Eur. Heart J. 33 (2012) 1787-1847.

[21] A. Mebazaa, M.B. Yilmaz, P. Levy, P. Ponikowski, W.F. Peacock, S. Laribi, et al., Recommendations on pre-hospital \& early hospital management of acute heart failure: a consensus paper from the Heart Failure Association of the European Society of Cardiology, the European Society of Emergency Medicine and the Society of Academic Emergency Medicine, Eur. J. Heart Fail. 17 (2015) 544-558.

[22] C. Mueller, M. Christ, M. Cowie, L. Cullen, A.S. Maisel, J. Masip, et al., European Society of Cardiology-Acute Cardiovascular Care Association Position paper on acute heart failure: a call for interdisciplinary care, Eur. Heart J. Acute Cardiovasc. Care (2015), http://dx.doi.org/10.1177/2048872615593279.

[23] P. Llorens, N. Manito Lorite, L. Manzano Espinosa, F.J. Martín-Sánchez, J. Comín Colet, F. Formiga, et al., Consensus on improving the care integrated of patients with acute heart failure, Emergencias 27 (2015) 245-266.

[24] Ò. Miró, F.W. Peacock, J.J. McMurray, H. Bueno, M. Christ, A.S. Maisel, et al., European Society of Cardiology - Acute Cardiovascular Care Association position paper on safe discharge of acute heart failure patients from the emergency department, Eur. Heart J. Acute Cardiovasc. Care (2016), http://dx.doi.org/10.1177/2048872616633853.

[25] S.A. Sternberg, A. Wershof Schwartz, S. Karunananthan, et al., The identification of frailty: a systematic literature review, J. Am. Geriatr. Soc. 59 (2011) 2129-2138.

[26] C.T. Cigolle, M.B. Ofstedal, Z. Tian, C.S. Blaum, Comparing models of frailty: the Health and Retirement Study, J. Am. Geriatr. Soc. 57 (2009) 830-839.

[27] L.P. Fried, C.M. Tangen, J. Walston, et al., Frailty in older adults: evidence for a phenotype, J. Gerontol. A Biol. Sci. Med. Sci. 56A (2001) M146-M156.

[28] M.D. Rothman, L. Leo Summers, T.M. Gill, Prognostic significance of potential frailty criteria, J. Am. Geriatr. Soc. 56 (2008) 2211-2216.

[29] K. Rockwood, A. Mitnitski, Frailty in relation to the accumulation of deficits, J. Gerontol. A Biol. Sci. Med. Sci. 62A (2007) 722-727.

[30] N.M. de Vries, J.B. Staal, C.D. van Ravensberg, J.S. Hobbelen, M.G. Olde Rikkert, M.W. Nijhuis van der Sanden, Outcome instruments to measure frailty: a systematic review, Ageing Res. Rev. 10 (2011) 104-114.

[31] R.M. Warnier, E. van Rossum, E. van Velthuijsen, W.J. Mulder, J.M. Schols, G.I. Kempen, Validity, reliability and feasibility of tools to identify frail older patients in inpatient hospital care: a systematic review, J. Nutr. Health Aging 20 (2016) 218-230.

[32] J. McCusker, F. Bellavance, S. Cardin, S. Trepanier, J. Verdon, O. Ardman, Detection of older people at increased risk of adverse health outcomes after an emergency visit: the ISAR screening tool, J. Am. Geriatr. Soc. 47 (1999) 1229-1237.

[33] S.W. Meldon, L.C. Mion, R.M. Palmer, B.L. Drew, JT. Connor, L. Lewicki, et al., A brief risk stratification tool to predict repeat emergency department visits and hospitalizations in older patients discharged from the emergency department, Acad. Emerg. Med. 10 (2003) 224-232.

[34] F. Salvi, V. Morichi, A. Grilli, L. Lancioni, L. Spazzafumo, S. Polonara, A.M. Abbatecola, G. De Tommaso, P. Dessi-Fulgheri, F. Lattanzio, Screening for frailty in elderly emergency department patients by using the Identification of Seniors At Risk (ISAR), J. Nutr. Health Aging 16 (2012) 313-318.

[35] J.L. Yao, J. Fang, Q.Q. Lou, R.M. Anderson, A systematic review of the identification of seniors at risk (ISAR) tool for the prediction of adverse outcome in elderly patients seen in the emergency department, Int. J. Clin. Exp. Med. 8 (2015) 4778-4786.

[36] K. Singler, H.J. Heppner, A. Skutetzky, C. Sieber, M. Christ, U. Thiem, Predictive validity of the identification of seniors at risk screening tool in a german emergency department setting, Gerontology 60 (2013) 413-419.

[37] O. Theou, T.D. Brothers, A. Mitntiski, et al., Operationalization of frailty using eight commonly used scales and comparison of their ability to predict all cause mortality, J. Am. Geriatr. Soc. 61 (2013) 1537-1551.

[38] J.L. Sutton, R.L. Gould, S. Daley, M.C. Coulson, E.V. Ward, A.M. Butler, et al., Psychometric properties of multicomponent tools designed to assess frailty in older adults: a systematic review, BMC Geriatr. 16 (2016) 55.

[39] J. Afilalo, K.P. Alexander, M.J. Mack, M.S. Maurer, P. Green, L.A. Allen, et al., Frailty assessment in the cardiovascular care of older adults, J. Am. Coll. Cardiol. 63 (2014) 747-762.

[40] M.S. Anker, S. von Haehling, J. Springer, M. Banach, S.D. Anker, Highlights of mechanistic and therapeutic cachexia and sarcopenia research 2010 to 2012 and their relevance for cardiology, Arch. Med. Sci. 9 (2013) 166-171.

[41] I. Uchmanowicz, M. Wleklik, R.J. Gobbens, Frailty syndrome and self-care ability in elderly patients with heart failure, Clin. Interv. Aging 10 (2015) 871-877.

[42] O. Theou, L. Cann, J. Blodgett, L.M. Wallace, T.D. Brothers, K. Rockwood, Modifications to the frailty phenotype criteria: systematic review of the current literature and investigation of 262 frailty phenotypes in the Survey of Health, Ageing, and Retirement in Europe, Ageing Res. Rev. 21 (2015) 78-94.

[43] J.M. Guralnik, L. Ferrucci, E.M. Simonsick, M.E. Salive, R.B. Wallace, Lower-extremity function in persons over the age of 70 years as a predictor of subsequent disability, N. Engl. J. Med. 332 (1995) 556-561.

[44] J.M. Guralnik, E.M. Simonsick, L. Ferrucci, R.J. Glynn, L.F. Berkman, B. DG, et al., A short physical performance battery assessing lower extremity function: association with self-reported disability and prediction of mortality and nursing home admission, J. Gerontol. 49 (1994) M85-M94.

[45] C. Minneci, A.M. Mello, E. Mossello, S. Baldasseroni, L. Macchi, S. Cipolletti, et al. Comparative study of four physical performance measures as predictors of death, incident disability, and falls in unselected older persons: the insufficienza Cardiaca negli Anziani Residenti a Dicomano Study, J. Am. Geriatr. Soc. 63 (2015) $136-141$.

[46] S. Studenski, S. Perera, K. Patel, C. Rosano, K. Faulkner, M. Inzitari, et al., Gait speed and survival in older adults, JAMA 305 (2011) 50-58.

[47] A.X. Lo, J.P. Donnelly, G. McGwin Jr., V. Bittner, A. Ahmed, C.J. Brown, Impact of gait speed and instrumental activities of daily living on all-cause mortality in adults $\geq 65$ years with heart failure, Am. J. Cardiol. 115 (2015) 797-801.

[48] S. Mathias, U.S. Nayak, B. Isaacs, Balance in elderly patients: the "get-up and go" test, Arch. Phys. Med. Rehabil. 67 (1986) 387-389.

[49] R. Hwang, N.R. Morris, A. Mandrusiak, A. Mudge, J. Suna, J. Adsett, et al., Timed up and go test: a reliable and valid test in patients with chronic heart failure, J. Card. Fail. (2015), http://dx.doi.org/10.1016/j.cardfail.2015.09.018.

[50] G. Turner, A. Clegg, British Geriatrics Society, Age UK; Royal College of General Practioners, Best practice guidelines for the management of frailty: a British Geriatrics Society, Age UK and Royal College of General Practitioners report, Age Ageing 43 (2014) 744-747.

[51] A.J. Cruz-Jentoft, J.P. Baeyens, J.M. Bauer, Y. Boirie, T. Cederholm, F. Landi, et al. Sarcopenia: European consensus on definition and diagnosis: report of the European Working Group on Sarcopenia in Older People, Age Ageing 39 (2010) 412-423.

[52] Points to Consider on Frailty: Evaluation Instruments for Baseline Characterisation of Clinical Trial Populations, European Medicines Agency. Committee for Medicinal Products for Human Use, 2015.

[53] S. Volpato, M. Cavalieri, G. Guerra, et al., Performance-based functional assessment in older hospitalized patients: feasibility and clinical correlates, J. Gerontol. A Biol. Sci. Med. Sci. 63 (2008) 1393-1398.

[54] D. Chiarantini, S. Volpato, F. Sioulis, F. Bartalucci, L. Del Bianco, I. Mangani, et al. Lower extremity performance measures predict long-term prognosis in older patients hospitalized for heart failure, J. Card. Fail. 16 (2010) 390-395.

[55] S. Volpato, M. Cavalieri, F. Sioulis, G. Guerra, C. Maraldi, G. Zuliani, et al., Predictive value of the short physical performance battery following hospitalization in older patients, J. Gerontol. A Biol. Sci. Med. Sci. 66 (2011) 89-96.

[56] G. Ellis, M.A. Whitehead, D. Robinson, D. O'Neill, P. Langhorne, Comprehensive geriatric assessment for older adults admitted to hospital: meta-analysis of randomised controlled trials, BMJ 343 (2011) d6553.

[57] A. Pilotto, F. Addante, M. Franceschi, G. Leandro, G. Rengo, P. D'Ambrosio, et al., Multidimensional Prognostic Index based on a comprehensive geriatric assessment predicts short-term mortality in older patients with heart failure, Circ. Heart Fail. 3 (2010) 14-20.

[58] E. Sánchez, M.T. Vidán, J.A. Serra, F. Fernández-Avilés, H. Bueno, Prevalence of geriatric syndromes and impact on clinical and functional outcomes in older patients with acute cardiac diseases, Heart 97 (2011) 1602-1606.

[59] C. Rodríguez-Pascual, A. Vilches-Moraga, E. Paredes-Galán, A.I. Ferrero-Marinez, M Torrente-Carballido, F. Rodríguez-Artalejo, Comprehensive geriatric assessment and hospital mortality among older adults with decompensated heart failure, Am. Heart J. 164 (2012) 756-762.

[60] C. Rodriguez-Pascual, E. Paredes-Galan, A. Vilches-Moraga, A.I. Ferrero-Martinez, M Torrente-Carballido, F. Rodriguez-Artalejo, Comprehensive geriatric assessment and 2-year mortality in elderly patients hospitalized for heart failure, Circ. Cardiovasc. Qual. Outcomes 7 (2014) 251-258.

[61] F.J. Martín-Sánchez, C. Fernández Alonso, P. Gil Gregorio, Key points in healthcare of frail elders in the emergency department, Med. Clin. (Barc.) 140 (2013) 24-29.

[62] D.B. Rolfson, S.R. Majumdar, R.T. Tsuyuki, A. Tahir, K. Rockwood, Validity and reliability of the Edmonton Frail Scale, Age Ageing 35 (2006) 526-529.

[63] S.N. Hilmer, V. Perera, S. Mitchell, B.P. Murnion, J. Dent, B. Bajorek, et al., The assessment of frailty in older people in acute care, Australas. J. Ageing 28 (2009) 182-188.

[64] T.B. Hii, J.G. Lainchbury, P.G. Bridgman, Frailty in acute cardiology: comparison of a quick clinical assessment against a validated frailty assessment tool, Heart Lung Circ. 24 (2015) 551-556.

[65] R. Calvani, F. Marini, M. Cesari, M. Tosato, S.D. Anker, S. von Haehling, et al., Biomarkers for physical frailty and sarcopenia: state of the science and future developments, J. Cachex. Sarcopenia Muscle 6 (2015) 278-286.

[66] M.E. Charlson, P. Pompei, K.L. Ales, et al., A new method of classifying prognostic comorbidity in longitudinal studies: development and validation, J. Chronic Dis. 40 (1987) 373-383.

[67] F.I. Mahoney, D. Barthel, Functional evaluation: the Barthel Index, Md. State Med. J. 14 (1965) 56-61.

[68] F.J. Martín-Sánchez, V. Gil, P. Llorens, P. Herrero, J. Jacob, C. Fernández, et al., Barthel Index-Enhanced Feedback for Effective Cardiac Treatment (BI-EFFECT) study: contribution of the Barthel Index to the Heart Failure Risk Scoring System model in elderly adults with acute heart failure in the emergency department, J. Am. Geriatr. Soc. 60 (2012) 493-498.

[69] J.E. Morley, B. Vellas, G.A. van Kan, S.D. Anker, J.M. Bauer, R. Bernabei, et al., Frailty consensus: a call to action, J. Am. Med. Dir. Assoc. 14 (2013) 392-397.

[70] M.A. Rizzi, O.H. Torres Bonafonte, A. Alquezar, S. Herrera Mateo, P. Piñera, M. Puig, et al., Prognostic value and risk factors of delirium in emergency patients with decompensated heart failure, J. Am. Med. Dir. Assoc. 16 (2015) 799 (e1-6).

[71] S.K. Inouye, C.H. van Dyck, C.A. Alessi, S. Balkin, A.P. Siegal, R.I. Horwitz, Clarifying confusion: the confusion assessment method. A new method for detection of delirium, Ann. Intern. Med. 113 (1990) 941-948. 
[72] E.W. Ely, S.K. Inouye, G.R. Bernard, S. Gordon, J. Francis, L. May, et al., Delirium in mechanically ventilated patients: validity and reliability of the confusion assessment method for the intensive care unit (CAM-ICU), JAMA 286 (2001) 2703-2710.

73] E.K. Van de Meeberg, S. Festen, M. Kwant, R.R. Georg, G.J. Izaks, J.C. Ter Maaten, Improved detection of delirium, implementation and validation of the CAM-ICU in elderly emergency department patients, Eur. J. Emerg. Med. (2016), http://dx.doi. org/10.1097/MEJ.0000000000000380.

74] J.D. Cameron, R. Gallagher, S.J. Pressler, S.N. McLennan, C.F. Ski, G. Tofler, et al. Sensitivity and specificity of a five-minute cognitive screening test in patients with heart failure, J. Card. Fail. 22 (2016) 99-107.

[75] J. Cameron, L. Worrall-Carter, K. Page, S. Stewart, C.F. Ski, Screening for mild cognitive impairment in patients with heart failure: Montreal cognitive assessment versus mini mental state exam, Eur. J. Cardiovasc. Nurs. 12 (2013) 252-260.

[76] A. Cherubini, J. Oristrell, X. Pla, C. Ruggiero, R. Ferretti, G. Diestre, et al., The persistent exclusion of older patients from ongoing clinical trials regarding heart failure, Arch. Intern. Med. 171 (2011) 550-556.

[77] Ò. Miró, V. Gil, C. Müller, A. Mebazaa, H. Bueno, F.J. Martín-Sánchez, et al., How does a clinical trial fit into the real world? The RELAX-AHF study population into the EAHFE registry, Clin. Res. Cardiol. 104 (2015) 850-860.

[78] R.S. Boxer, A.M. Kenny, B.J. Schmotzer, M. Vest, J.J. Fiutem, I.L. Piña, A randomized controlled trial of high dose vitamin D3 in patients with heart failure, JACC Heart Fail. 1 (2013) 84-90.

[79] T.P. Ng, L. Feng, M.S. Nyunt, L. Feng, M. Niti, T. BY, et al., Nutritional, physical, cognitive, and combination interventions and frailty reversal among older adults: a randomized controlled trial, Am. J. Med. 128 (2015) 1225-1236.

[80] S.H. Ewe, N. Ajmone Marsan, M. Pepi, et al., Impact of left ventricular systolic func tion on clinical and echocardiographic outcomes following transcatheter aortic valve implantation for severe aortic stenosis, Am. Heart J. 160 (2010) 1113-1120.

[81] M. Singh, C.S. Rihal, R.J. Lennon, J.A. Spertus, K.S. Nair, V.L. Roger, Influence of frailty and health status on outcomes in patients with coronary disease undergoing percutaneous revascularization, Circ. Cardiovasc. Qual. Outcomes 4 (2011) 496-502.

[82] P. Green, A.E. Woglom, P. Genereux, et al., The impact of frailty status on survival after transcatheter aortic valve replacement in older adults with severe aortic stenosis: a single-center experience, J. Am. Coll. Cardiol. Intv. 5 (2012) 974-981.

[83] A. Sepehri, T. Beggs, A. Hassan, C. Rigatto, C. Shaw-Daigle, N. Tangri, et al., The impact of frailty on outcomes after cardiac surgery: a systematic review, J. Thorac Cardiovasc. Surg. 148 (2014) 3110-3117.

[84] A. Dominguez-Rodriguez, P. Abreu-Gonzalez, A. Jimenez-Sosa, J. Gonzalez, N. Caballero-Estevez, F.V. Martín-Casañas, et al., The impact of frailty in olde patients with non-ischaemic cardiomyopathy after implantation of cardiac resynchronization therapy defibrillator, Europace 17 (2015) 598-602.

[85] J. Afilalo, M.J. Eisenberg, J.F. Morin, H. Bergman, J. Monette, N. Noiseux, et al., Gait speed as an incremental predictor of mortality and major morbidity in elderly patients undergoing cardiac surgery, J. Am. Coll. Cardiol. 56 (2010) 1668-1676.

[86] J. Afilalo, S. Mottillo, M.J. Eisenberg, K.P. Alexander, N. Noiseux, L.P. Perrault, et al., Addition of frailty and disability to cardiac surgery risk scores identifies elderly patients at high risk of mortality or major morbidity, Circ. Cardiovasc. Qual. Outcomes 5 (2012) 222-228

[87] T.N. Robinson, B. Eiseman, J.I. Wallace, S.D. Church, K.K. McFann, S.M. Pfister, et al., Redefining geriatric preoperative assessment using frailty, disability and comorbidity, Ann. Surg. 250 (2009) 449-455.

[88] G. Güder, F.H. Rutten, Comorbidity of heart failure and chronic obstructive pulmonary disease: more than coincidence, Curr. Heart Fail. Rep. 11 (2014) 337-346.

[89] S.A. Hill, R.A. Booth, P.L. Santaguida, A. Don-Wauchope, J.A. Brown, M. Oremus, et al. Use of BNP and NT-proBNP for the diagnosis of heart failure in the emergency department: a systematic review of the evidence, Heart Fail. Rev. 19 (2014) 421-438.

[90] H.F. Groenveld, J.L. Januzzi, K. Damman, J. van Wijngaarden, H.L. Hillege, D.J. van Veldhuisen, et al., Anemia and mortality in heart failure patients: a systematic review and meta-analysis, J. Am. Coll. Cardiol. 52 (2008) 818-827.

[91] A. Mebazaa, E. Gayat, J. Lassus, T. Meas, C. Mueller, A. Maggioni, et al., Association between elevated blood glucose and outcome in acute heart failure: results from an international observational cohort, J. Am. Coll. Cardiol. 61 (2013) 820-829.

[92] K. Damman, M.A. Valente, V. AA, C.M. O'Connor, D.J. van Veldhuisen, H.L. Hillege, Renal impairment, worsening renal function, and outcome in patients with heart failure: an updated meta-analysis, Eur. Heart J. 35 (2014) 455-469.

[93] C.S. Lee, C.V. Chien, J.T. Bidwell, J.M. Gelow, Q.E. Denfeld, R. Masterson Creber, et al., Comorbidity profiles and inpatient outcomes during hospitalization for heart failure: an analysis of the U.S. Nationwide inpatient sample, BMC Cardiovasc. Disord. 14 (2014), 73.

[94] A.J. Cruz-Jentoft, B. Boland, L. Rexach, Drug therapy optimization at the end of life, Drugs Aging 29 (2012) 511-521.

[95] H.M. Holmes, G.A. Sachs, J.W. Shega, G.W. Hougham, D. Cox Hayley, W. Dale, Integrating palliative medicine into the care of persons with advanced dementia: identifying appropriate medication use, J. Am. Geriatr. Soc. 56 (2008) 1306-1311.

[96] O. Miró, R. Escoda, FJ. Martín-Sánchez, P. Herrero, J. Jacob, A. Alquézar, et al. Patients' perception of quality of emergency department care for acute heart failure: the CALPERICA study, Emergencias 27 (2015) 161-168. 